\title{
Does the revised intubating laryngeal tube (ILTS-D2) perform better than the intubating laryngeal mask (Fastrach)? - a randomised simulation research study
}

Thomas Ott $^{1 *}$ D, Katharina Tschöpe ${ }^{1}$, Gerrit Toenges ${ }^{2}$, Holger Buggenhagen ${ }^{3}$, Kristin Engelhard ${ }^{1}$ and Marc Kriege ${ }^{1}$

\begin{abstract}
Background: The intubating laryngeal tube (ILTS-DTM) and the intubating laryngeal mask (Fastrach ${ }^{\mathrm{TM}}$ ) are devices that facilitate both extraglottic application and blind tracheal intubation. A revised model of the iLTS-D (for scientific reasons called ILTS-D2) has been designed but not yet evaluated. Therefore, we compared the ILTS-D2 with the established Fastrach under controlled conditions in a prospective randomised controlled simulation research study.

Methods: After ethical approval, we randomised 126 medical students into two groups. Each participant received either Fastrach or ILTS-D2 to perform five consecutive ventilation attempts in a manikin. The primary endpoint was the time to ventilation in the last attempt of using the devices as extraglottic devices. Secondary endpoints were the time to tracheal intubation and the success rates.

Results: There was no relevant difference between the two devices in the time to ventilation in the last of five attempts (Fastrach: median 14 s [IQR: 12-15]; ILTS-D2: median 13 s [IQR: 12-15], $p=0.592)$. Secondary endpoints showed a $2 \mathrm{~s}$ faster blind tracheal intubation using the Fastrach than using the ILTS-D2 (Fastrach: median $14 \mathrm{~s}$ [IQR: 13-17]; ILTS-D2: median 16 s [IQR: 15-20] $p$ < 0.001). For both devices, the success rates were 100\% in the last attempt.
\end{abstract}

Conclusions: Concerning extraglottic airway management, we could not detect a relevant difference between the revised ILTS-D2 and the Fastrach under laboratory conditions. We advocate for an evaluation of the ILTS-D2 in randomised controlled clinical trials.

Trial registration: Identifier at clinicaltrials.gov: NCT03542747. May 31, 2018

Keywords: [MeSH tree numbers]: simulation, Airway management [E02.041], Intubation [E05.497.578], Laryngeal masks [E05.497.578.475], Manikins [J01.897.280.500.545.129.400]

\section{Background}

Extraglottic airway devices are recommended for health care providers who are inexperienced in tracheal intubation and as a rescue procedure in difficult airway

\footnotetext{
* Correspondence: ottth@uni-mainz.de

'Department of Anaesthesiology, Medical Centre of the Johannes Gutenberg University, Langenbeckstr. 1, 55131 Mainz, Germany

Full list of author information is available at the end of the article
}

situations [1]. However, tracheal intubation tends to show benefits in critically ill patients compared to extraglottic devises [2]. The Fastrach ${ }^{\text {Ta }}$ (FT-LM; Teleflex, Athlone, Ireland) intubating laryngeal mask is a well-described extraglottic ventilation device and is recommended for providers untrained in tracheal intubation [3]. The iLTS$\mathrm{D}^{\mathrm{Tw}}$ intubating laryngeal tube (VBM, Sulz a. N., Germany) is also used to facilitate a secondary tracheal intubation.

(c) The Author(s). 2020 Open Access This article is licensed under a Creative Commons Attribution 4.0 International License, which permits use, sharing, adaptation, distribution and reproduction in any medium or format, as long as you give appropriate credit to the original author(s) and the source, provide a link to the Creative Commons licence, and indicate if changes were made. The images or other third party material in this article are included in the article's Creative Commons licence, unless indicated otherwise in a credit line to the material. If material is not included in the article's Creative Commons licence and your intended use is not permitted by statutory regulation or exceeds the permitted use, you will need to obtain permission directly from the copyright holder. To view a copy of this licence, visit http://creativecommons.org/licenses/by/4.0/ The Creative Commons Public Domain Dedication waiver (http://creativecommons.org/publicdomain/zero/1.0/) applies to the data made available in this article, unless otherwise stated in a credit line to the data. 
First described in 2013, only a few studies have been published regarding its use [4,5]. A revised version of the iLTS-D for scientific reasons called 'ILTS-D2' has been developed. Now, we evaluated this ILTS-D2 in an experimental setting using a manikin to prove its applicability [6]. In a prospective randomised controlled simulation research study, we compared the new ILTS-D2 with the FTLM by using final year medical students as a representative sample of inexperienced airway providers with broad general medical knowledge. The primary endpoint was the time to ventilation when used as an extraglottic airway device in the last of five consecutive ventilation attempts. Our null hypothesis was that there is no difference in time to ventilation in the last of five attempts between the ILTS-D2 and the FT-LM when used as extraglottic devices.

\section{Methods}

\section{Study design and time period}

After ethical board approval (State Physicans' Chamber of Rhineland-Palatinate, Registration Number: 2018133,000-E., 18. May 2018), we conducted a randomised two-armed simulation research study with medical students as unbound samples. One group applied the FTLM, and the other group applied the ILTS-D2 at a 1:1 ratio regarding the number of participants in both study groups. The study was conducted in our departmental simulation centre in June 2018.

\section{Participants}

Medical students in their final year of medical school represent a sample with good theoretical knowledge but a lack of clinical experience and are therefore recommended for using extraglottic devices in emergency situations. A total of 126 medical students were recruited during their mandatory practical training periods.

\section{ILTS-D2}

The revised ILTS-D2 differs from its predecessor in a number of regards $[4,5]$; for the sake of clarity and conciseness, all cited lengths are measured from the tip (placed in the oesophagus entrance) along the convex frame of the device. The ILTS-D2 is $27 \mathrm{~cm}$, thus $1 \mathrm{~cm}$ shorter than its predecessor. In both devices, the oesophageal cuff is similar, and the laryngeal orifice for ventilation and tube guidance is positioned from $6.5 \mathrm{~cm}$ to $9.5 \mathrm{~cm}$ from the distal margin. In comparison to the iLTS-D, the pharyngeal cuff of the ILTS-D2 is $2.5 \mathrm{~cm}$ more proximal and shorter in its longitudinal dimension (iLTS-D: $7.5-14.5 \mathrm{~cm}$, ILTS-D2: $9.5-16 \mathrm{~cm}$ ). Thus, the distance between the proximal and the distal cuff is longer in the ILTS-D2 than in its predecessor (iLTS-D: 6 $\mathrm{cm}$, ILTS-D2: $7.5 \mathrm{~cm}$ ). The ILTS-D2 is slightly wider between the cuffs than the iLTS-D (Fig. 1). Both devices fit sizes 4 and 5 of a classical laryngeal tube and indicate that the maximum size of tracheal tube that can be applied though the device is 8.0. A separately delivered $100 \mathrm{ml}$ syringe for inflating the cuffs is colour coded according to the different sizes. A separately delivered tube can be inserted into the trachea through the laryngeal orifice that is shaped as a ramp. The angle of the tube guidance is approximately 35 to 40 degrees. The ILTSD2 covers conventional laryngeal tube sizes 2 to 5 [7].

The ILTS-D2 is introduced along the hard palatinate until an elastic resistance indicates a proper fit in the oesophageal entrance. After inflation of the cuffs by the colour-coded syringe, extraglottic ventilation can be established. Then, the tube can be inserted through the device into the trachea.

\section{Fastrach $^{\mathrm{TM}}$}

The FT-LM is an established device evaluated for extraglottic and tracheal airway management [8]. We used the size 4 FT-LM with the provided tracheal tube.

\section{Manikin}

We used the Laerdal Kelly ${ }^{\mathrm{mm}}$ ALS (Laerdal ${ }^{\circ}$ Medical AS, Stavanger, Norway) manikin for this study. Manikins cannot completely replicate human anatomy. However, we have chosen this manikin because its airway offers one of the closest replications of the human anatomy for airway management simulation [9]. The manikin was placed on an emergency room stretcher, and the thorax was exposed.

\section{Data collection}

After written informed consent was signed, the following demographic data were recorded: gender, age, and previous experience in airway management in patients: number of applications of 1) tracheal intubations, 2) laryngeal masks and 3) laryngeal tubes. Furthermore, professional qualifications such as paramedic, specialised nurses in anaesthesiology, medical clerkships and electives in anaesthesiology were protocolled. The participants were then randomised by flipping a coin to represent either the ILTS-D2 or the FT-LM. Each participant was familiarised with the particular device by a standardised introduction.

Only the allocated device was shown to the participant. The lubricated device with deflated cuffs, the appropriate tracheal tube, the syringe and the ventilation bag were placed on a table directly beside the manikin. First the extraglottic application then the tracheal intubation were explained by Peyton's four-step approach: 1) demonstration in real time, 2) deconstruction (explanation and clarifying questions), 3) comprehension (explanation from participant to instructor), 4) execution by the participant [10]. The last step (execution) constituted the first of five attempts to place the device. 


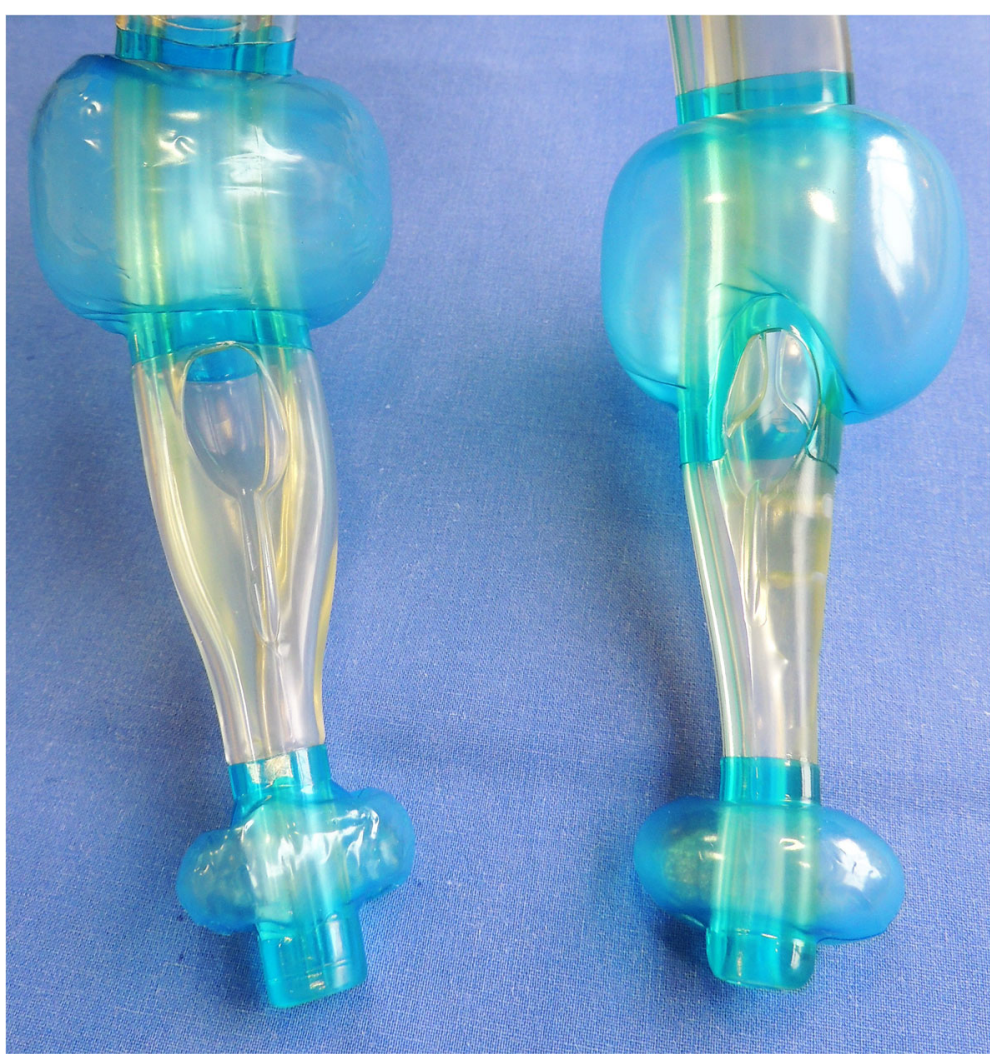

Fig. 1 ILTS-D2 (left) and its precursor iLTS-D ${ }^{\circledast}$ (right) in direct comparison. Details are described in the main text

A total of five consecutive attempts were performed by each participant with one device. A stopwatch was started as soon as the participant touched the device and was stopped when the first chest rise was detectable [11]. After that, the stopwatch was started again as soon as the participant touched the tracheal tube and was stopped when the first chest rise was detectable. For both extraglottic ventilation and tracheal intubation, the time was not censored. However, censoring would occur due to the participants' discontinuation. The instructors were not allowed to help during the attempts. If there was a chest rise, the attempt was counted as successful. If there was no chest rise or if the participant himself or herself discontinued the attempt, the attempt was counted as unsuccessful.

\section{Outcome measures}

The primary endpoint was the time to ventilation in seconds (s) of extraglottic attempt five. Secondary endpoints were time to ventilation and intubation of all other attempts and success rates.

\section{Sample size}

In March 2018, our sample size was determined by the actual number of students beginning the semester, 134, out of which 126 were recruited. The median time to ventilation using the Fastrach in our previous study (used as pilot data) for extraglottic ventilation was $20 \mathrm{~s}$ with a standard deviation of $5 \mathrm{~s}$ [4]. A reduction of $3 \mathrm{~s}$ was considered a clinically relevant difference in time for application of an airway instrument in the fifth attempt. With 63 participants per group, a difference in the medians of $3 \mathrm{~s}$ would have been detected with a power of $90.39 \%$ using a two-sided, level $\alpha=0.05$ Wilcoxon ranksum test.

\section{Randomisation and blinding}

Randomisation was performed by a coin flip (heads or tails) by two of the authors ( $\mathrm{TO}$ and $\mathrm{KT}$ ) before data collection. Heads was allocated to FT-LM and tails to ILTS-D2; this allocation was alternated every 20 participants. To gain an equal distribution of the level of previous experience, randomisation was stratified by professional qualification, clerkships and electives at a 1:1 ratio with regard to the devices. The participants could not be blinded to the devices for airway management because they had to apply the device.

\section{Statistical analysis}

We used Microsoft Excel 2010 (Microsoft $^{\ominus}$ Corporate Headquarters, Redmond, USA) and IBM SPSS Statistics 
Version 23 ( $\mathrm{IBM}^{\circ}$, Ehningen, Germany). Considering that the data are non-normally distributed, data are shown as medians, interquartile ranges (IQRs), minima and maxima.

As no censored observations were present for the data of the primary endpoint (time to ventilation in attempt five of extraglottic application), the two groups were compared by a two-sided Wilcoxon rank-sum test. A $p$ value $<0.05$ was considered statistically significant.

Regarding the secondary endpoints, censored observations were present for a few participants. Hence, group comparisons for the secondary endpoints were conducted either with a two-sided Wilcoxon rank-sum test if no attempts were discontinued by participants or with the log-rank test if attempts were discontinued by participants. $P$-values for secondary endpoints are given for exploratory reasons only.

\section{Results}

\section{Primary endpoint: Extraglottic airway management}

In the last of five attempts, no difference in time to ventilation between the FT-LM and the ILTS-D2 could be detected (FT-LM: median: 14 s (IQR: 12-15), ILTS-D2: median: $13 \mathrm{~s}$ (IQR: 12-15), $p=0.692$ ) (Table 1$)$.

\section{Secondary endpoints: Extraglottic airway management and tracheal intubation through the device}

In extraglottic application attempts one to four, as with the primary endpoint no difference in time to ventilation between the FT-LM and the ILTS-D2 could be detected. The time to ventilation continuously decreased from attempt one to five. All participants successfully established extraglottic application with both devices.

Tracheal intubation tended to be $4 \mathrm{~s}$ faster in attempt one and $2 \mathrm{~s}$ faster in attempt five using the FT-LM compared to the ILTS-D2 (attempt five: FT-LM: median: 14 s (IQR: 13-17), ILTS-D2: median: $16 \mathrm{~s}$ (IQR: 15-20), $p<0.001)$. The time to ventilation continuously decreased from attempt one to five (Table 1).

The success rates for extraglottic application over all attempts were $100 \%$.

The success rates for tracheal intubation over all attempts was $98-100 \%$ with FT-LM and $95-100 \%$ with ILTS-D2, with a $100 \%$ success rate in both groups for attempt five (Table 2).

\section{Participants}

We obtained written informed consent from 126 participants from 28 May to 20 June 2018. A total of 63 participants were allocated to the FT-LM and 63 to the ILTS-D2 (Fig. 2). The median age was 27 years (FT-LM: median: 27 (IQR: 20-30), ILTS-D2: median: 27 (IQR: 26-30), $p=$ $0.744)$ in both groups. Further details are cited in Table 3.
Table 1 Time to ventilation in seconds for extraglottic application and tracheal intubation using the Fastrach and the ILTS-D2

\begin{tabular}{|c|c|c|c|c|c|}
\hline & & Median & IQR & Min / Max & $P$ \\
\hline \multicolumn{6}{|c|}{ Extraglottic application } \\
\hline \multirow[t]{2}{*}{ Attempt 1} & Fastrach & 19 & $16-22$ & $12 / 30$ & \\
\hline & ILTS-D2 & 17 & $15-21$ & $11 / 70$ & $0.183^{\mathrm{a}}$ \\
\hline \multirow[t]{2}{*}{ Attempt 2} & Fastrach & 16 & $13-17$ & $11 / 34$ & \\
\hline & ILTS-D2 & 15 & $13-18$ & $10 / 43$ & $0.982^{\mathrm{a}}$ \\
\hline \multirow[t]{2}{*}{ Attempt 3} & Fastrach & 15 & $13-17$ & $10 / 25$ & \\
\hline & ILTS-D2 & 15 & $13-17$ & $10 / 25$ & $0.647^{\mathrm{a}}$ \\
\hline \multirow[t]{2}{*}{ Attempt 4} & Fastrach & 14 & $13-16$ & $9 / 21$ & \\
\hline & ILTS-D2 & 14 & $12-16$ & $9 / 27$ & $0.846^{a}$ \\
\hline \multirow[t]{2}{*}{ Attempt 5} & Fastrach & 14 & $12-15$ & $8 / 20$ & \\
\hline & ILTS-D2 & 13 & $12-15$ & $9 / 28$ & $0.592^{\mathrm{ac}}$, \\
\hline \multicolumn{6}{|c|}{ Tracheal intubation } \\
\hline \multirow[t]{2}{*}{ Attempt 1} & Fastrach & 19 & $17-22$ & $14 / 41$ & \\
\hline & ILTS-D2 & 23 & $20-26$ & $16 / 160$ & $<0.001^{\mathrm{a}}$ \\
\hline \multirow[t]{2}{*}{ Attempt 2} & Fastrach & 16 & $15-19$ & $12 / 32$ & \\
\hline & ILTS-D2 & 20 & $17-22$ & $13 / 140$ & $<0.001^{\mathrm{b}}$ \\
\hline \multirow[t]{2}{*}{ Attempt 3} & Fastrach & 15 & $14-18$ & $11 / 33$ & \\
\hline & ILTS-D2 & 18 & $16-21$ & $12 / 168$ & $<0.001^{\mathrm{b}}$ \\
\hline \multirow[t]{2}{*}{ Attempt 4} & Fastrach & 15 & $13-18$ & $11 / 35$ & \\
\hline & ILTS-D2 & 18 & $15-22$ & $12 / 114$ & $0.002^{b}$ \\
\hline \multirow[t]{2}{*}{ Attempt 5} & Fastrach & 14 & $13-17$ & $10 / 27$ & \\
\hline & ILTS-D2 & 16 & $15-20$ & $12 / 112$ & $<0.001^{a}$ \\
\hline
\end{tabular}

${ }^{\mathrm{a}}$ Wilcoxon rank-sum test; ${ }^{\mathrm{b}}$ Log-rank test; ${ }^{\mathrm{c}}$ primary endpoint

Time to ventilation in seconds for extraglottic application and tracheal intubation using the Fastrach ${ }^{T M}$ and the ILTS-D2. Medians, interquartile ranges (IQRs), minima (Min), maxima (Max) and P-values of the particular statistics regarding participant-related censoring: Wilcoxon rank-sum test (attempts without censoring: all extraglottic attempts and intubation attempts 1 and 5), Log-rank test (attempts with censoring: intubation attempts 2, 3 and 4)

Table 2 Success rates. Success rates concerning extraglottic ventilation were $100 \%$ over all five attempts in both devices

\begin{tabular}{lllll}
\hline Tracheal intubation & & Success rate (\%) & $\begin{array}{l}n \text { success / } \\
n \text { total }\end{array}$ & $n$ missing \\
\hline Attempt 1 & Fastrach & 100 & $63 / 63$ & 0 \\
& ILTS-D2 & 98 & $62 / 63$ & 0 \\
Attempt 2 & Fastrach & 100 & $63 / 63$ & 0 \\
& ILTS-D2 & 97 & $61 / 63$ & 0 \\
Attempt 3 & Fastrach & 98 & $62 / 63$ & 0 \\
& ILTS-D2 & 95 & $60 / 63$ & 0 \\
Attempt 4 & Fastrach & 98 & $61 / 62$ & 1 \\
& ILTS-D2 & 98 & $62 / 63$ & 0 \\
Attempt 5 & Fastrach & 100 & $63 / 63$ & 0 \\
& ILTS-D2 & 100 & $63 / 63$ & 0
\end{tabular}

Success rates in percent (\%) for the particular attempt exclusively concerning tracheal intubation. Number $(n)$ of successful ventilations and total number ( $n$ total) of participants for the particular attempt. Number of missing data ( $n$ missing) for the particular attempt 


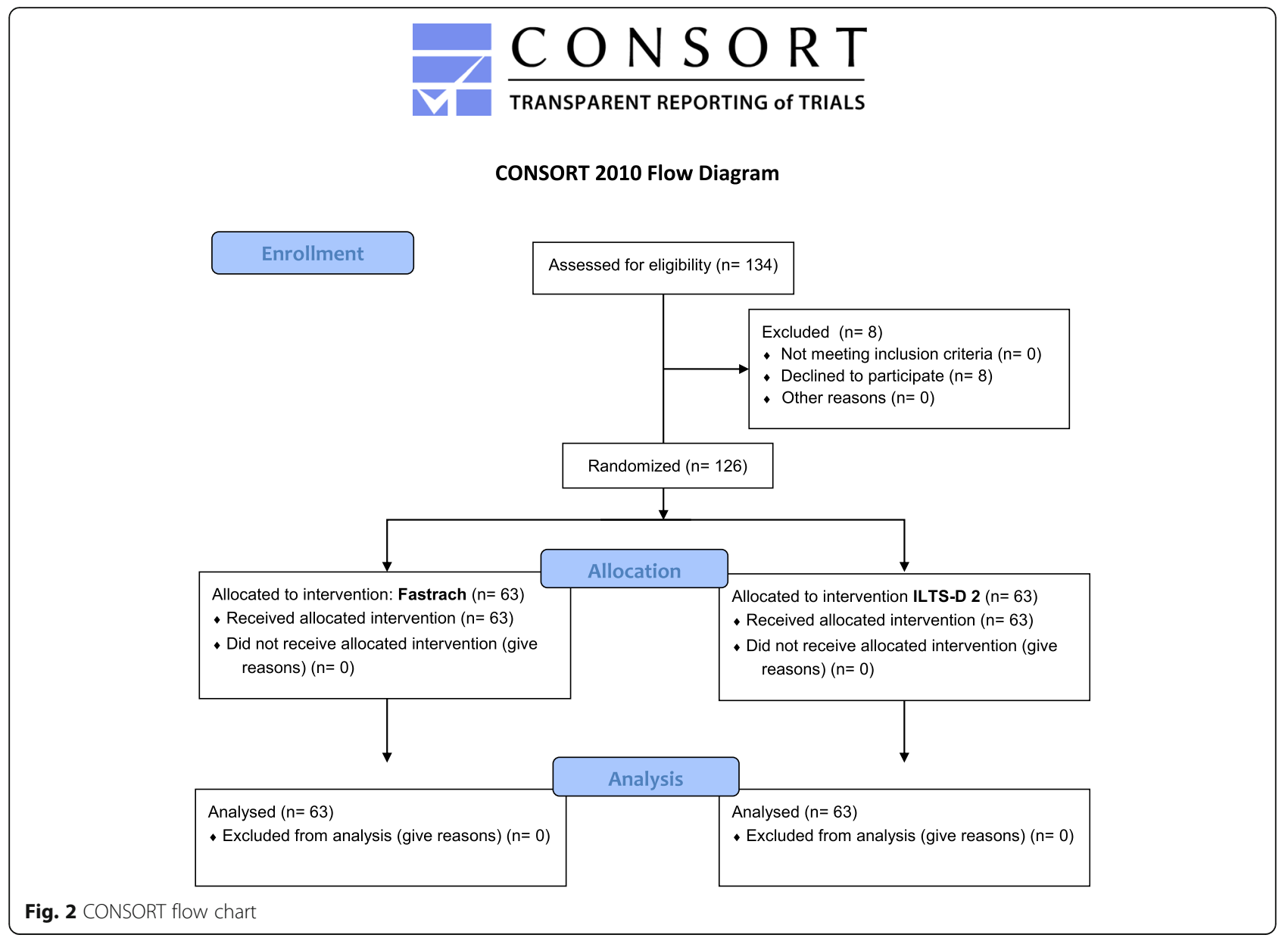

\section{Discussion}

The present study shows that the revised ITLS-D2 as an extraglottic airway device is as easy to apply as the FTLM in terms of efficacy in a simulated environment. The median time to ventilation was $14 \mathrm{~s}$ with the Fastrach ${ }^{\mathrm{Tm}}$ and $13 \mathrm{~s}$ with the ILTS-D2. Secondary endpoints concerning extraglottic application tended to show no relevant differences in attempts one to four as well. Based on these findings, the revised ILTS-D2 is considered a well-applicable extraglottic airway device for inexperienced providers, at least under laboratory conditions.

However, the time to intubation tended to be longer for the ILTS-D2 than for the FT-LM. The pharyngeal cuff of the ILTS-D2 is positioned at a more cranial level of the pharynx in comparison to its precursor, which might cause a relative delay of intubation in comparison to the FT-LM. The ITLS-D2 is constructed for blind intubation but can also be combined with fibreoptic guided intubation through the ILTS-D. Undoubtedly, intubation endoscopy is the most reliable technique in this context, but it requires advanced skills and is, therefore, reserved for experienced airway management providers only [12]. However, the success rate using the ILTS-D2 was comparable with that of the FT-LM over all five attempts. Thus, the ITLS-D2 can be considered a stand-alone device for blind intubation under laboratory conditions, nevertheless fibreoptic control generally is recommendable for tracheal intubation in this context of extraglottic airway devices.

\section{Comparison to previous studies}

The present study yielded timeframes that are valid for simulation research studies. The predecessor of the ILTS-D2 yielded timeframes as an extraglottic device of $14.5 \mathrm{~s}$ [4]. The time to ventilation using the FT-LM was in the range of 8 to $29 \mathrm{~s}$ [13-15] and as an intubation conduit was approximately $20 \mathrm{~s}[15,16]$. Furthermore, the FT-LM inheres broad evidence as a ventilation and intubation device. Therefore, in the present study, the FT-LM was used as a reference device $[8,17]$.

\section{Limitations}

Simulation research lacks translation to real patients. In particular, evaluations of airway devices inhere alternations of reality due to the quality of tissue, absence of mucus and other anatomic aspects [9]. Furthermore, the simulated situation was strictly focused on airway management, not on 
Table 3 Demographics of the participants

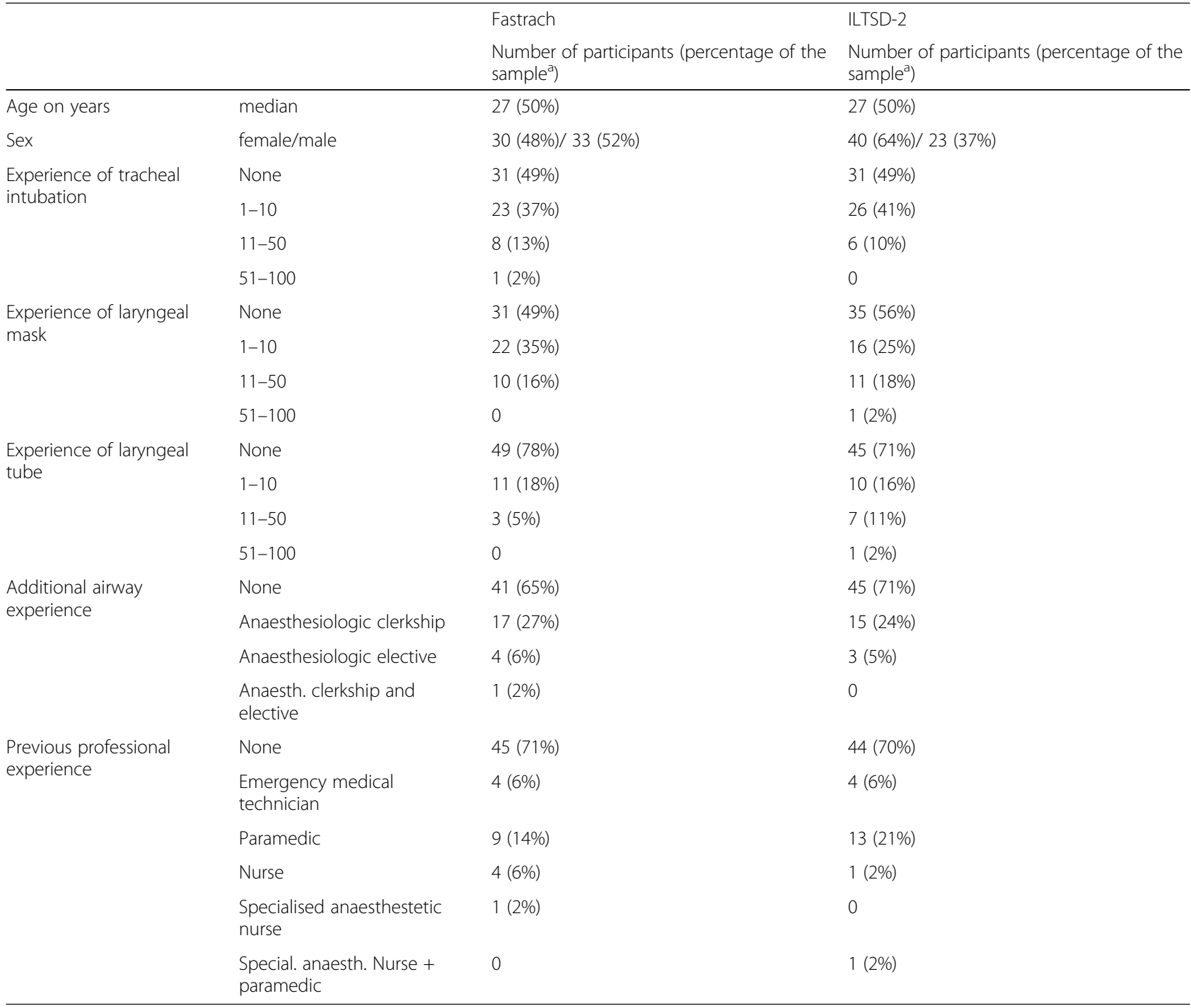

${ }^{\mathrm{a}}$ sum of percent occasionally exceeds 100 due to mathematical rounding

any other medical aspects like emergency situations or insertion techniques of the particular device $[1,18,19]$. Nevertheless, it is recommended to train and evaluate providers with manikins due to the possibility of standardisation of situational and anatomy-related conditions [20]. Analogue to pharmacologic principals, the authors believe that airway devices ought to be evaluated under laboratory conditions before application in patients. Cook et al. noted this problem and recommended a structured analysis of novel airway devices, similar to the developmental process of drugs [21].

\section{Clinical implications}

After the first attempt, both devices presented with an early reduction of time to ventilation. However, there was still a decrease in time to ventilation from attempt four to five. Therefore, we did not reach the end of a learning curve with five application attempts. These findings indicate that even under simulated conditions, more than five attempts may be necessary for inexperienced providers to reach proficiency with these devices.

\section{Conclusions}

Concerning extraglottic airway management, we could not detect a relevant difference between the revised ILTSD2 and the FT-LM under laboratory conditions. Concerning intubation, in our sample, participants intubated the trachea $2 \mathrm{~s}$ faster using the FT-LM than using the ILTSD2; however, this amount of time was not relevantly different. Under these conditions, the authors advocate for further investigations in controlled clinical trials.

Acknowledgements

Our sincere thanks to the Chair of our Department of Anaesthesiology, the staff coordination and the Department of Research and Training for their great support while conducting the study. 


\section{Authors' contributions}

TO and MK designed the study and drafted the manuscript. TO and KT conducted the data collection of the study, GT provided the statistical analysis, $\mathrm{HB}$ and $\mathrm{KE}$ have made substantial contributions to the interpretation of the results and the draft of the manuscript. All authors had the opportunity to review the final version of the manuscript and have approved their permission to publish the manuscript.

\section{Funding}

The authors declare that there is no source of financial funding VBM Medizintechnik GmbH (VBM, Sulz, Germany) provided the 'ILTS-D2' for the present study. The study was planned, designed, performed, analysed and written without any support by VBM Medizintechnik GmbH. There was no financial, personal or scientific influence by VBM Medizintechnik GmbH onto the study.

\section{Availability of data and materials}

The datasets generated and analysed during the current study are available in the Mendeley Data repository under Digital Object Identifier (DOI): https// www.doi.org: https://doi.org/10.17632/sj5362f4n7.1

\section{Ethics approval and consent to participate}

The appropriate Ethical board of the State Physicans' Chamber of RhinelandPalatinate, Deutschhausplatz 3, 55116 Mainz approved the study under the Registration Number: "2018-133000-Epidemioloige" on 18. May 2018. All participants signed a written informed consent before participation in the study. Participation was voluntary.

\section{Consent for publication}

Not applicable.

\section{Competing interests}

The authors declare that there is no conflict of interests.

\section{Author details}

'Department of Anaesthesiology, Medical Centre of the Johannes Gutenberg University, Langenbeckstr. 1, 55131 Mainz, Germany. ${ }^{2}$ Institute of Medical Biostatistics, Epidemiology, and Informatics, Medical Centre of the Johannes Gutenberg University, Mainz, Germany. ${ }^{3}$ Rudolf-Frey Lernklinik Central Education Platform, Medical Centre of the Johannes Gutenberg University, Mainz, Germany.

Received: 19 November 2019 Accepted: 29 April 2020

Published online: 11 May 2020

\section{References}

1. Frerk C, Mitchell VS, McNarry AF, Mendonca C, Bhagrath R, Patel A, et al. Difficult airway society 2015 guidelines for management of unanticipated difficult intubation in adults. Br J Anaesth. 2015;115(6):827-48.

2. Benoit JL, Gerecht RB, Steuerwald MT, McMullan JT. Endotracheal intubation versus supraglottic airway placement in out-of-hospital cardiac arrest: a meta-analysis. Resuscitation. 2015;93:20-6.

3. Timmermann A, Russo SG, Crozier TA, Eich C, Mundt B, Albrecht B, et al. Novices ventilate and intubate quicker and safer via intubating laryngeal mask than by conventional bag-mask ventilation and laryngoscopy. Anesthesiology. 2007;107(4):570-6.

4. Ott T, Fischer M, Limbach T, Schmidtmann I, Piepho T, Noppens RR. The novel intubating laryngeal tube (iLTS-D) is comparable to the intubating laryngeal mask (Fastrach) - a prospective randomised manikin study. Scand J Trauma Resusc Emerg Med. 2015;23(1):44.

5. Bergold MN, Kahle S, Schultzik T, Bucheler M, Byhahn C. Intubating laryngeal tube suction disposable: initial clinical experiences with a novel device for endotracheal intubation. Anaesthesist. 2016;65(1):30-5.

6. Cheng A, Kessler D, Mackinnon R, Chang TP, Nadkarni VM, Hunt EA, et al. Reporting guidelines for health care simulation research: extensions to the CONSORT and STROBE statements. Adv Simul (Lond). 2016;1:25.

7. Kriege M, Alflen C, Eisel J, Ott T, Piepho T, Noppens RR. Evaluation of the optimal cuff volume and cuff pressure of the revised laryngeal tube "LTS-D" in surgical patients. BMC Anesthesiol. 2017;17(1):19
8. Ydemann M, Rovsing $L$, Lindekaer AL, Olsen KS. Intubation of the morbidly obese patient: GlideScope((R)) vs Fastrach. Acta Anaesthesiol Scand. 2012; 56(6):755-61.

9. Schalk R, Eichler K, Bergold MN, Weber CF, Zacharowski K, Meininger D, et al. A radiographic comparison of human airway anatomy and airway manikins--implications for manikin-based testing of artificial airways. Resuscitation. 2015;92:129-36.

10. Munster T, Stosch C, Hindrichs N, Franklin J, Matthes J. Peyton's 4-StepsApproach in comparison: Medium-term effects on learning external chest compression - a pilot study. GMS J Med Educ. 2016;33(4):Doc60.

11. Perkins GD, Handley AJ, Koster RW, Castren M, Smyth MA, Olasveengen T, et al. European resuscitation council guidelines for resuscitation 2015: section 2. Adult basic life support and automated external defibrillation. Resuscitation. 2015;95:81-99.

12. Preece $G, N g$ I, Lee $K$, Mezzavia P, Krieser R, Williams DL, et al. A randomised controlled trial comparing fibreoptic-guided tracheal intubation through two supraglottic devices: Ambu(R) AuraGain laryngeal mask and LMA(R) Fastrach. Anaesth Intensive Care. 2018;46(5):474-9.

13. Schalte G, Stoppe C, Aktas M, Coburn M, Rex S, Schwarz M, et al. Laypersons can successfully place supraglottic airways with 3 minutes of training. A comparison of four different devices in the manikin. Scand J Trauma Resus. 2011:19:60-8

14. Castle N, Pillay Y, Spencer N. Insertion of six different supraglottic airway devices whilst wearing chemical, biological, radiation, nuclear-personal protective equipment: a manikin study. Anaesthesia. 2011;66(11):983-8.

15. Ott T, Barth A, Kriege M, Jahn-Eimermacher A, Piepho T, Noppens RR. The novel video-assisted intubating laryngeal mask Totaltrack compared to the intubating laryngeal mask Fastrach - a controlled randomized manikin study. Acta Anaesthesiol Scand. 2017;61(4):381-9.

16. Sherren PB, Kong ML, Chang S. Comparison of the Macintosh, McCoy, Airtraq laryngoscopes and the intubating laryngeal mask airway in a difficult airway with manual in-line stabilisation a cross-over simulation-based study. Eur J Anaesthesiol. 2013:30(9):544-9.

17. Wiesmann T, Doffert J, Steinfeldt T. Peripheral regional anesthesia without any complications - a dream comes true?! Anasthesiol Intensivmed Notfallmed Schmerzther. 2018;53(4):252-68.

18. Piepho T, Cavus E, Noppens R, Byhahn C, Dorges V, Zwissler B, et al. S1 guidelines on airway management. Anaesthesist. 2015;64(11):859-73.

19. Sorbello M, Petrini F. Supraglottic airway devices: the search for the best insertion technique or the time to change our point of view? Turk $J$ Anaesthesiol Reanim. 2017;45(2):76-82.

20. Cumin D, Weller JM, Henderson K, Merry AF. Standards for simulation in anaesthesia: creating confidence in the tools. Brit J Anaesth. 2010;105(1):4551.

21. Cook TM, Kelly FE. Time to abandon the 'vintage' laryngeal mask airway and adopt second-generation supraglottic airway devices as first choice. $\mathrm{Br}$ J Anaesth. 2015;115(4):497-9.

\section{Publisher's Note}

Springer Nature remains neutral with regard to jurisdictional claims in published maps and institutional affiliations.

Ready to submit your research? Choose BMC and benefit from:

- fast, convenient online submission

- thorough peer review by experienced researchers in your field

- rapid publication on acceptance

- support for research data, including large and complex data types

- gold Open Access which fosters wider collaboration and increased citations

- maximum visibility for your research: over $100 \mathrm{M}$ website views per year

At $\mathrm{BMC}$, research is always in progress.

Learn more biomedcentral.com/submissions 